\title{
Resenha
}

RUI, Taniele. Nas tramas do crack: etnografia da abję̧ão. São Paulo, Terceiro Nome, 2014, 397 pp.

\section{Pedra, cimento, corpos e moralidades: sobre crack e enfrentamentos urbanos}

Tiago Lemões

Universidade Federal do Rio Grande do Sul, Porto Alegre, RS, Brasil

tiagolemoes@gmail.com

(...) há que se reconhecer, o crack teve positividade, produziu política

(Rui, 2014:121).

É no cenário de produção de um corte, uma separação e uma diferenciação dos usuários de crack enquanto uma população particular - sujeitos específicos de intervenções e alvo de políticas públicas direcionadas - que se localiza a densa e potente etnografia de Taniele Rui. Ao percorrer caminhos cruzados por sujeitos, práticas e moralidades ancorados analiticamente em uma trama social, corporal e territorial, a sensibilidade etnográfica da autora proporciona revelações desconcertantes sobre o enredamento dos usuários em relações com os espaços, os objetos, o mundo do tráfico, os agentes e as instituições estatais de assistência, cuidado e repressão.

Nas tramas do crack: etnografia da abję̧ão é resultado de uma imersão etnográfica que conjuga diferentes cenários de uso e comércio de crack, entre as cidades de Campinas e São Paulo, e a análise de materiais de imprensa publicados sobre o tema. Dividido em três partes e subdividido em seis capítulos, o livro não apresenta, como bem infere a autora, uma hipótese central ou a comprovação de uma série de hipóteses. Desperdiçar esforços é querer identificar uma teoria ou um autor que figure como espinha dorsal da discussão empreendida. Ao longo da narrativa, os autores são chamados a existir, sem exaustão, na medida em que contribuem para iluminar diferentes debates (como corporalidade, desigualdade social, violência, marginalidades urbanas, políticas públicas, pobreza, tráfico de drogas, segurança pública e sistema prisional) e para conceder amplitude a determinados argumentos, uma vez 
que os autores e seus “textos só são relevantes quando nos fazem ver mais, não menos” (:24). Essa postura ousada e vigilante perpassa o diálogo da antropóloga com os autores ao longo dos capítulos, o que destarte permite repensar a relação que se estabelece com a produção acadêmica e privilegiar a potência das experiências etnográficas na implosão de determinados enquadramentos teóricos.

Na primeira parte, a etnografia tem como ponto de partida um duplo percurso histórico: o que se refere à "inserção" da antropóloga em campo, com ênfase nos processos de aproximação e negociação tramados na relação com agentes dos programas de redução de danos (PRDs); e a trajetória de constituição e transformação destes programas no Brasil, que culmina no contexto de produção de uma "questão de saúde pública". O cruzamento entre territorialidade, sociabilidade e corporalidade abjeta integra o esforço empreendido na segunda parte do livro, a partir da descrição dos espaços de usos do crack e das fronteiras físicas e simbólicas que eles evocam. Por fim, é na terceira parte do trabalho que se conformam interpretações sobre a reflexividade dos usuários frente aos distintos arranjos de inscrições corporais agenciados no processo de aproximação/afastamento de rotulações e estigmas. Aqui as reflexões desdobram-se em um experimento analítico: ao seguir os cachimbos utilizados para o consumo do crack, a autora infere a relação pessoas/objetos à medida que estas categorias se misturam e pessoalizam os cachimbos, que se inscrevem em relações sociais e delineiam campos de ação estatal.

Interessada, inicialmente, em demonstrar as potencialidades do crack na produção e reformulação de políticas públicas, a antropóloga apresenta o contexto de surgimento, transformação e inscrição institucional dos PRDs. Este processo, relacionado à diminuição do consumo de drogas na forma injetável, explicita suas consequências na maneira pela qual a redução de danos passa a ser compreendida e dinamizada por políticas públicas e também pelo "novo" viés através do qual o Estado entra em contato com uma população historicamente capturada como problema legal e moral. Por isso, a maioria das cenas etnográficas tem como porta de entrada as interações decorrentes do trabalho de redução de danos conduzido pela ONG É de Lei, em São Paulo, e pelo Centro de Referência Municipal de DST/Aids, em Campinas.

Estes núcleos de intervenção emergiram nos anos 1990, dentro de um cenário de associação entre casos de contaminação por HIV e uso de drogas injetáveis, em continuidade à proliferação internacional de programas de trocas de seringas que, sob o efeito de iniciativas governamentais, da sociedade civil e de ativistas do campo da saúde pública, passam a conformar a base das práticas conduzidas nos atuais PRDs. Enquanto resposta à epidemia de 
Aids, estes programas começaram a atuar sobre o consumo de outros tipos de drogas, outras doenças sexualmente transmissíveis, diversificando metodologias de trabalho e inserindo-se em campos de luta por espaços de legitimidade institucional, sobretudo, contra as lógicas de tratamento de dependência química calcadas na abstinência e na internação fechada, aos moldes das comunidades terapêuticas.

Ao traçar o processo de constituição destas políticas, Rui nos mostra que é neste cenário que o aumento do consumo de crack, e o pânico moral que o acompanha, passa a ser decisivo tanto na criação e efetivação de políticas públicas específicas aos usuários de drogas, quanto na contestação da origem dos recursos destinados aos novos serviços. Tal processo desemboca em uma atmosfera fragmentada, conflituosa e paradoxal na qual a formulação e a implementação de políticas públicas cambaleiam entre as retóricas oficiais que reconhecem o “atraso histórico" no posicionamento sobre a questão; as práticas e compreensões multiformes sobre a redução de danos; e as estratégias locais dos PRDs que, entre riscos de extinção ou necessidades de expansão, explicitam o descompasso no processo de composição do uso e abuso de drogas como uma "questão de saúde pública". Essa produção da saúde pública envolve também a transformação de categorias e sujeitos e a constituição de novas arenas de intervenção, traduzindo-se na dramática e sempre inconclusa passagem do delinquente para o paciente, transpondo o desvio e a dependência para a lógica do risco sanitário.

A etnografia, no entanto, vai além. Discute e problematiza o múltiplo e conflituoso campo de consolidação institucional das políticas públicas para, então, percorrer caminhos na trilha dos agentes redutores de danos, por entre cenários urbanos de comércio e uso de drogas. É assim que as fronteiras, os espaços e os usos vão sendo articulados nas tramas do crack, desvelados pelas andanças entre becos, praças públicas, cantos de rua, buracos cavados na terra, viadutos, beira de córregos, construções abandonadas e mesmo espaços não tão anônimos, como a "cracolândia": lugar de recorrentes intervenções estatais, imobiliárias, midiáticas. Nestes percursos, Rui experimenta lugares que, tal como os corpos, portam abjeção e propulsionam ambiguidades na medida em que neles a violência real é tanto sofrida quanto perpetrada, mas é nestas territorialidades que também se encontram, a um só tempo, proteção e perigo, ameaça e afeto. E são estas territorializações que estigmatizam segmentos urbanos, mas que constroem redes de sociabilidade na tensão das relações de poder inerentes à negociação de limites socioespaciais. Essa multiplicidade, que instiga a questionar como, com quem e de que modo as relações se estabelecem, é exatamente o que conduz o movimento reflexivo da autora, demarcado por três espaços de uso do crack: em 
Campinas, a linha de trem do Paranapanema e o prédio da Vila Industrial; em São Paulo, o espaço público nacionalmente conhecido como "cracolândia".

Mobilizada pela tentativa de interpretação destes espaços, Rui argumenta que é na produção destas territorialidades que são evocados limites em interações que permeiam escalas distintas de violência, gestão social e policial, segregação espacial e moral. É pelo engajamento nestas interações que os usuários se tornam abjetos de um tipo de relação como fica claro nas descrições da "famosa boca do Paranapanema", onde usuários, traficantes e outros personagens do circuito local mantêm vinculações assentadas em cuidados e proteções, mas também em conflitos e evitações. É impactante a maneira pela qual os arranjos de consumo são balizados pelas tensas relações entre traficantes e usuários, sobretudo quando estes se tornam foco de jocosidades, humilhações e violência física, que se acirram quanto maior o grau de proximidade com a figura do nóia. Essa categoria, de acusação e de assunção, refere-se aos que fazem uso extremado da substância e se tornam, assim, alvo de classificações sociais e morais que concedem contorno às formas de ocupar e transitar pelos espaços de consumo e venda de substâncias ilegais.

No entanto, a especificidade dos complexos morais que dramatizam estas relações reporta nossas atenções para mecanismos de gestão de espaços, usos e condutas elaborados em confluência com uma ética do uso de drogas, atrelada às ideias e valores do Primeiro Comando da Capital, o PCC. Em diálogo com outros trabalhos etnográficos sobre o tema, Rui expõe os principais eixos que guiam essa valoração moral: a necessidade de autovigilância para evitar a perda de respeito entre os pares; a vigilância constante sobre os que "perderam o respeito" e a possibilidade de circular e consumir livremente em determinados espaços; ou até mesmo a expulsão definitiva dos usuários que "se afastam" da ética vigente nestes locais. Assim, a correlação entre delimitação espacial e valoração moral se manifesta na redução dos espaços de trânsito e permanência dos usuários conforme a intensidade do cuidado que empregam sobre si. Isso ocorre pelo consenso de que o uso extremo da substância compromete o "grau de dignidade" mínimo para a negociação dos movimentos de fluidez e fixação daqueles sujeitos nos espaços de tráfico e consumo de drogas.

Mas, se na "boca do Paranapanema" o imperativo do autocontrole se coloca como parte de uma gestão moral e espacial propagada pelo PCC, é no prédio da Vila Industrial e na "cracolândia" que outros enfrentamentos urbanos entram em cena. Nestes cenários, o foco privilegiado de análise são justamente as formas “oficiais” de gestão e controle de populações por meio das faces múltiplas do Estado: assistência, repressão, cuidado e vigilância. Através 
dos agentes e de suas ações, sejam elas públicas, performatizadas, midiatizadas ou contínuas e cotidianas, as intervenções estatais escancaram os modos de sujeição dos usuários. O caso do prédio da Vila Industrial - que se tornou habitação coletiva de pessoas em situação de rua e usuários de crack -, deixa claro que o combate a estas populações é, sobretudo, um combate aos seus espaços de concentração. Além destes traços de enfrentamento urbano, as grandes operações lançadas contra aquela habitação coletiva especificam a multiplicidade de atores envolvidos na mediação, denúncia e rejeição de seus habitantes. Com um olhar mais próximo, uma cadeia complexa de tensões espaciais e sociais se desvela, dinamizada pela violência policial, pela hostilidade e clamor público da vizinhança, por programas municipais de gestão dos "indesejáveis" e pela visibilidade de sujeitos ávidos para a concorrência de cargos públicos - complexidade de atores, interesses políticos e práticas de visibilidade estatal potencializada pelos usuários de crack, os espaços que ocupam e os discursos ambíguos que mobilizam.

No entanto, se a gama de interesses em jogo se mostra apreensível nas midiatizadas ações do poder público investidas em uma construção paralisada, são em locais como a "cracolândia" paulistana que a multiplicidade de associações e interações cotidianas parecem zombar de qualquer tentativa de entendimento sistemático. Essa famosa territorialidade de uso do crack é palco de uma tensa convivência envolvendo agentes da segurança pública, traficantes e usuários e um assédio cotidiano de profissionais da imprensa, pesquisadores, grupos religiosos, ativistas de direitos humanos e serviços de saúde e assistência. Agentes, instituições e práticas que circundam, assombram e constituem este "lugar que se deve evitar, lugar de perigo, lugar degradado. Também de degredo. E, por isso mesmo, em muitos aspectos, lugar de grande atração" (:223).

Sem pretender esgotar as reflexões sobre todos estes intercâmbios que concorrem para a constituição daquele espaço, a antropóloga debruça-se sobre as funções estatais de controle e cuidado e seus impactos na dinâmica de consumo local. Destaco que é justamente deste recorte analítico que uma constatação se depreende: definitivamente, o Estado não está ausente na "cracolândia". Ao contrário, ele é parte constitutiva das práticas e dos significados que ali são negociados. As forças estatais estão lá em demasia, com suas faces assistenciais e repressivas, subjugando, punindo, ajudando e encaminhando. Com isso, na busca pelos modos de produção da cidade em condições precárias, a autora guia suas reflexões questionando-se como estas forças atuam naquele espaço, de que forma, na sua multiplicidade de intervenções, o Estado se faz presente na tentativa de fixar uma territorialidade que guarda fascínio e poder na dimensão plural e móvel que lhe constitui. 
A meu ver, o mais instigante é que, dentre tantos esforços reflexivos erigidos por Rui ante a multiplicidade de interações com a qual se depara, a descrição etnográfica nos permite compreender a "cracolândia" não só como um espaço de intervenção estatal, mas também de produção do próprio Estado a partir da interação cotidiana entre diferentes agentes envolvidos. Se ações estandardizadas e midiatizadas mobilizam a materialização do poder estatal enquanto uma realidade compósita, coesa e centralista, os relacionamentos cotidianos, ainda que explicitem a complexidade dos sujeitos em interação, nunca são amistosos. E não o são pelo fato de o vínculo institucional ser utilizado no reforço de determinadas fronteiras entre grupos alvo de intervenções e os agentes estatais. Ao serem "flagrados" conversando com uma agente da guarda municipal, a etnógrafa e os redutores de danos foram advertidos por um usuário sobre a necessidade de "escolher um lado": "nós é que somos seus amigos. De que lado vocês estão afinal?” (:232). O convite para ocupar uma posição entre a inapreensível efervescência de atores e instituições reitera os limites da interação com as instituições de caráter repressivo - ainda que aquela agente da guarda se destacasse por desenvolver oficinas de desenho com as crianças usuárias de crack. Aqui, nas suas margens, o Estado é "recomposto". Posto novamente "no lugar" justamente quando uma pretensa centralidade se esvai na inconstância e complexidade de seus agentes.

Se até então as reflexões se concentraram, sobretudo, nas formas de gestão dos espaços e dos sujeitos que produzem as (e são produzidos por) territorialidades abjetas, a última parte do livro evoca a reflexividade dos usuários sobre os corpos, as vidas e as moralidades que atravessam a situação em que se encontram. Para tal, a discussão sobre pessoas, substâncias, corpos e coisas, localiza a reflexividade em uma trama de relações, de vínculos, de discursos sobre higiene, limpeza, degredo, vergonha e vontades declaradas de controle das alterações corporais. Ante os discursos que se acomodam nos corpos, os usuários passam a reivindicar o direito de cultivarem um corpo e um espaço limpos, o que possibilita, no limite, a manutenção de vínculos de afeto e ajuda - malgrado as possibilidades reduzidas de asseio corporal no universo das ruas. Assim como a sujeira, as marcas corporais são carregadas de valoração moral e criam tipos distintos de usuários de crack: as marcas nos dedos, nos dentes, a rouquidão da voz e a magreza dos corpos integram o tipo mais extremo deles, o nóia, do qual a maioria busca afastar-se discursivamente. O seu inverso positivo, apresentado, sobretudo, no ganho de peso, mobiliza vontades de controle do uso como forma de domínio do corpo - vontades que devem ser declaradas e reiteradas na medida em que se sabe que degredo corporal implica em "perda de dignidade". 
E ao falar em dignidade, os cachimbos entram em cena, no último capítulo, não como meros instrumentos de uso. Ao segui-los e traçar suas trajetórias, a autora percebe o trânsito entre objetos, agência e pessoas, em atenção à capacidade daqueles artefatos de incitar relações sociais com coisas, lugares, pessoas, instituições e ideias. É assim que, entre os usuários, os cachimbos atuam como demarcadores de um grau de humanidade e dignidade a que alguém pode chegar: ter o seu próprio cachimbo torna-se uma demonstração mínima de cuidado de si. Mas a potência agenciadora destes objetos não fica só por aqui. Entre os redutores de danos, os cachimbos agenciam formas de aproximação e preparam o terreno para a constituição de vínculos com os usuários. É a partir destes vínculos que condições materiais e emocionais são forjadas na intenção de incitá-los a refletir sobre a situação em que se encontram e perceber que possuem "direitos a ter direitos". São, também, estes mesmos cachimbos que mobilizam a política de redução de danos, pois é em torno de seus modos de uso que os PRDs formulam e executam suas ações. Da mesma forma, estes objetos instigam classificações morais e justificam apreensões policiais, "em um processo metonímico para classificar seus portadores e justificar a ação dos órgãos de segurança pública" (:335). A revelação não poderia ser mais instigante: o cachimbo, por não ser (só) um cachimbo, conjuga e conecta políticas públicas, intervenção estatal, direitos e luta política.

Por todos os argumentos aqui expostos, fica claro que Nas tramas do crack traz inquietações potentes para o debate antropológico, sobretudo pela exposição dos mecanismos pelos quais o Estado produz zonas de degradação espacial e moral ao capturar, "recuperar", assujeitar ou rejeitar determinadas "populações" que habitam as margens e questionam hegemônicos limites corporais, espaciais e morais. Ao acompanhar Taniele Rui nessa ousada imersão etnográfica, o leitor entra em contato com esses complexos dispositivos de produção e de gestão de um "problema social”. Mas não só. Ao nos depararmos com a complexidade e agência dos interlocutores, temos acesso à força corporal, moral e política com a qual estes mesmos sujeitos (categorizados como usuários) impulsionam e recriam aparatos e técnicas políticas que recaem sobre pessoas e territórios, criam alteridades extremadas e cultivam corpos abjetos que perturbam regras, valores e identidades. Não deixam, também, de conectar suas reflexões sobre vidas, corpos e territorialidades abjetas às suas avaliações sobre dignidade, direitos e cidadania. Em suma, é por ousar e impressionar tanto, que o livro se torna leitura obrigatória aos viciados em etnografias que desestabilizam e fazem pensar, e muito, sobre a violência prática e discursiva que atravessa a administração dos conflitos urbanos contemporâneos. 